\title{
STATE OF MOBILE BANKING IN TANZANIA AND SECURITY ISSUES
}

\author{
Bossi Masamila \\ School of Computing, Dublin Institute of Technology, Dublin, Ireland
}

\begin{abstract}
Mobile technology offers an unprecedented growth opportunity for banking industry in Tanzania. As the economy continues to prosper, increasingly affluent consumers and underbanked segments create demand for new financial products and services. Many consumers in Tanzania have mobile phones, but not bank accounts. Therefore, the mobile channel presents an effective way to connect them to the national financial grid. For the local banks, going mobile may increase banks opportunities to unlock the inherent potential of underbanked segments. This paper addresses the current state, future prospects, and security challenges to the usage of mobile banking in Tanzania.
\end{abstract}

\section{KEYWORDS}

Security, Mobile Banking, Mobile Payment

\section{INTRODUCTION}

The developing world has witnessed the wide spread and use of mobile technology faster than any other technology in human history. As the result impressive surge of message services has been developed that can goes beyond personal communication needs. For example, information such as agricultural data reports, healthcare reminders, e-mails, Internet, Short Message Service (SMS), financial transactions, and Multimedia Message Service (MMS) are becoming commonplace. Also, special personalized services such as mobile banking are becoming common to the underbanked segments. Mobile banking is the phenomenal expansion of mobile phone network in developing markets that provide an opportunity to operate virtual bank accounts through a mobile phone. As [1] pointed out, mobile banking provides financial services such as money transfer, bill payment, savings and other financial transaction services without having to rely exclusively on cash to previously underserved segments.

In their report "State of the Industry 2013" [2], there is over 219 mobile money deployments worldwide with 203 million subscribers in 84 countries. According to their report, Africa is leading with over $\mathbf{1 2 3}$ mobile banking deployments (i.e. 52\%). Also, they pointed out that despite the growth of registered customers, activating customer is the challenge to many service providers. For example, out of $\mathbf{2 0 3}$ million subscribers only $\mathbf{2 9 . 9 \%}$ are active [2]

In Tanzania, like any developing country, building bank branches is expensive and often is seen as unprofitable by traditional banks in part due to sheer size of transactions. On the other hand, Internet, another channel for banking services is often not feasible to the large part of the population. This is due to a lack of reliable distributed computer networks. As a result, many large populations in Tanzania are considered "underbanked", that is they do not have access to formal banking services. Despite various initiatives, the level of Financial Inclusion in Tanzania is still relatively low. For example, in 2013 the penetration level was 17 percent of adult 
population (about 3.7 million) that has access to bank accounts [3]. On the other end, mobile phone usage is on the rise. According to the statistics from TCRA, the number of mobile phone subscribers has increased up to $\mathbf{5 8 \%}$ with over $\mathbf{2 7}$ million subscribers [4]. In this case mobile banking is the only available feasible means to provide mass market alternative to branch banking in Tanzania. With the current four deployments (Tigo Pesa, M-Pesa, Ezy-Pesa and AirtelMoney [5], mobile banking presents the potential to extend beyond traditional bank coverage to include rural area, which are characterised with low population density and poor infrastructure. Statistics from BOT shows that there are over $\mathbf{3 0}$ million mobile banking subscribers. And over $\mathbf{7 0 0}$ million transactions worth of $\boldsymbol{U S} \$ \mathbf{1 2 . 3}$ billion has been conducted since mobile money was launched [6]. Figure 1 shows the comparison of mobile banking in Kenya and Tanzania in yearly transaction value.

Financial access points as reported by [7] has increased to 10 folds as compared to brick-mortar access points and are within reach (as shown in Figure 2 ) to the majority of the population. This increase means more people are connected to the national financial grid, which is the sign of economic growth.

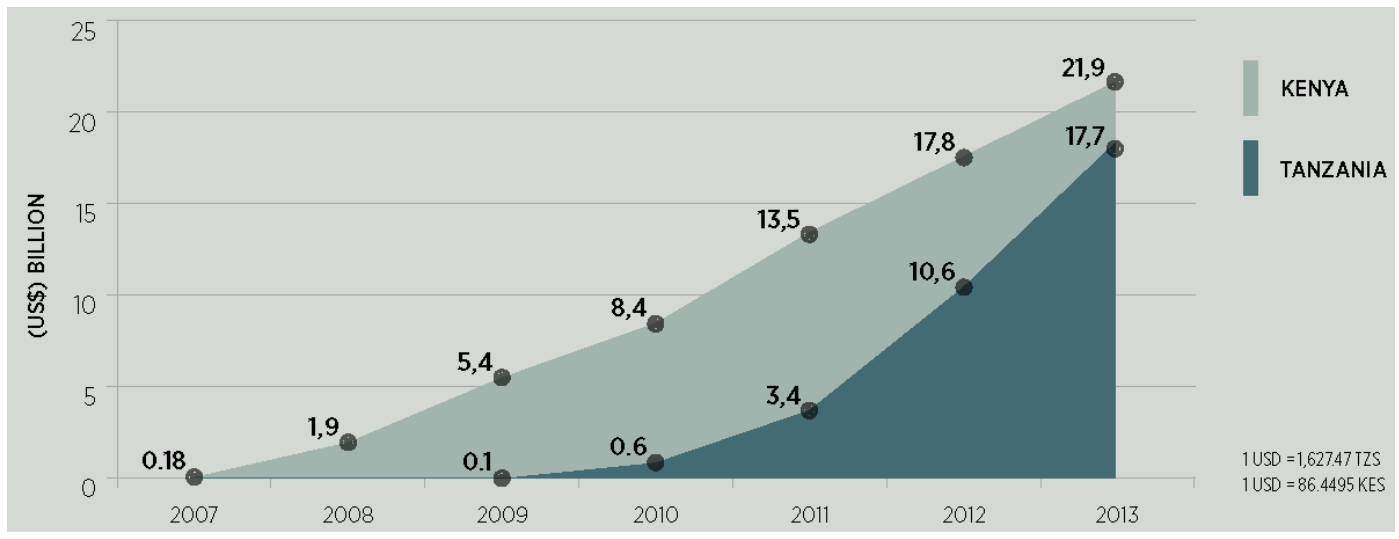

Figure 1 Comparing Mobile banking in Kenya and Tanzania yearly Transaction value [6]

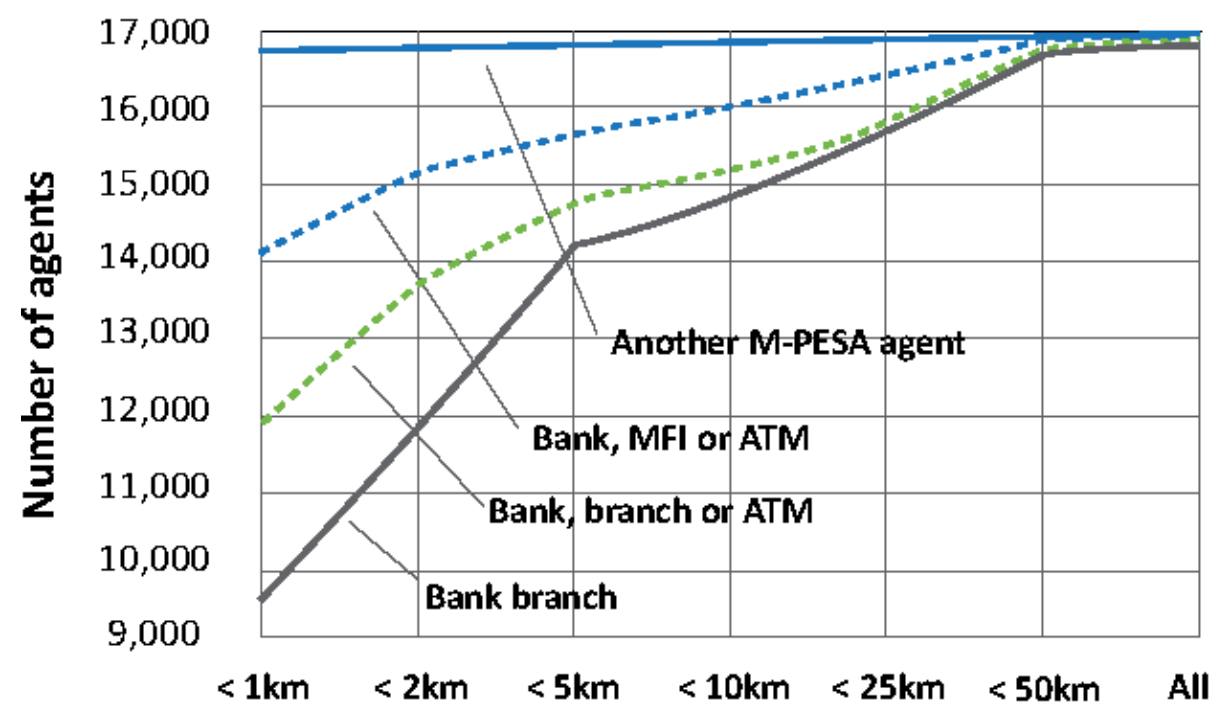

Figure 2: How close M-Pesa outlets are to other mobile banking agents and banking outlets [7] 
International Journal of Network Security \& Its Applications (IJNSA), Vol.6, No.4, July 2014

In this paper the following headings are discussed: Part two discusses mobile banking in Tanzania that includes current mobile banking deployments and their corresponding market share. Part three of this paper discusses mobile banking ecosystem in Tanzania. In this section we discuss key player and their involvement with mobile banking services. Part four discusses security challenges in mobile banking in Tanzania. Part five presents the discussion and the conclusion of this paper.

\section{MOBILE BANKING IN TANZANIA}

In Tanzania, mobile banking was first introduced by E-fulusi Africa Limited in Partnership with FMBE bank through Mobipawa platform. Mobipawa was operator independent platform that allowed subscribers to transfer, receive, save and withdraw money as well as purchase goods and services through the use of mobile phones.

Vodacom Tanzania in collaboration with Vodafone launched Vodafone M-Pesa (a version of MPesa in Kenya) in April 2008. M-Pesa is a mobile money transfer platform that can be operated by MNO in emerging markets. With M-Pesa, customers are able to send money to any other mobile customer via a simple text-based transaction [8]. Recipients of such transfers are able to convert the e-money back into cash at any authorised M-Pesa agent across the country.

M-Pesa uses aggregator model to manage agent network. The use of aggregators has reduced the complexity of agent management as M-Pesa does not deal directly with thousands of outlets spread out across the country. Also, this model has improved cash management, for example, balancing of cash float issues between different outlets caused by regional imbalances between deposits and withdrawals [9]. Recently, Vodacom Tanzania and Commercial Bank of Africa (CBA) have launched a banking service named M-Pawa that will allow Tanzanians, who are MPesa customer, to save and borrow money on their mobile phones. In addition, Vodacom's MPesa is integrated with $\mathbf{2 1}$ commercial banks in the country. It is also the preferred payment solution for over 200 businesses in country[10].

Another provider is Zantel. Zantel launched Z-Pesa (which known as Ezy-Pesa) in 2008. EzyPesa was first introduced in Zanzibar market, but it has since extended its service to include the mainland. Initially, it was intended to support money transfer (i.e. sending and receiving money), but this service has expanded to include payment such as bill and merchants payments. Ezy-Pesa uses E-Fulusi Mobile Transaction Switch (EFMTS) developed by E-fulusi.

In 2009, Airtel (previous knows as Zain) introduced AirtelMoney, a mobile banking platform developed by Hamisco Oberthur technologies [11]. AirtelMoney was launched simultaneously in Tanzania and Kenya with the aim to link micro-payments to merchants that would overcome the need to convert money into cash. With AirtelMoney, customer can make a direct purchase to the merchant and also it can be used as the channel to move cash from one location to another. Airtel through AirtelMoney is collaborating with merchants who moves larger amounts of money, and has inter-linked with several banks of which customers can move their virtual money into their AirtelMoney accounts [12].

Tigo, a mobile network operator, introduced another version of mobile banking called Tigo Pesa. Tigo Pesa was launched in September, 2010, initially with the ability help customer to send and receive money. Its function has been expanded to include payment services such as bill, merchants and personal-to-personal payment.

Currently, the mobile banking market share (as shown in Figure 3) is dominated by Vodacom's M-Pesa with 53\% followed by Tigo-Pesa with $\mathbf{1 8 \%}$ and AirtelMoney with 13\%[6]. Fig. 1 shows the mobile banking market share distribution taken from the article titled "Enabling Mobile 
Money Policies in Tanzania" by[6]. In the same way, M-Pesa has 17,000 agents nationwide of which $62 \%$ are exclusively dedicated to M-Pesa [7]. Furthermore, [7] indicates that half of the agents do more than $\mathbf{3 0}$ transactions per day. And mobile agents outnumber all other financial outlets by almost 10 to 1 .

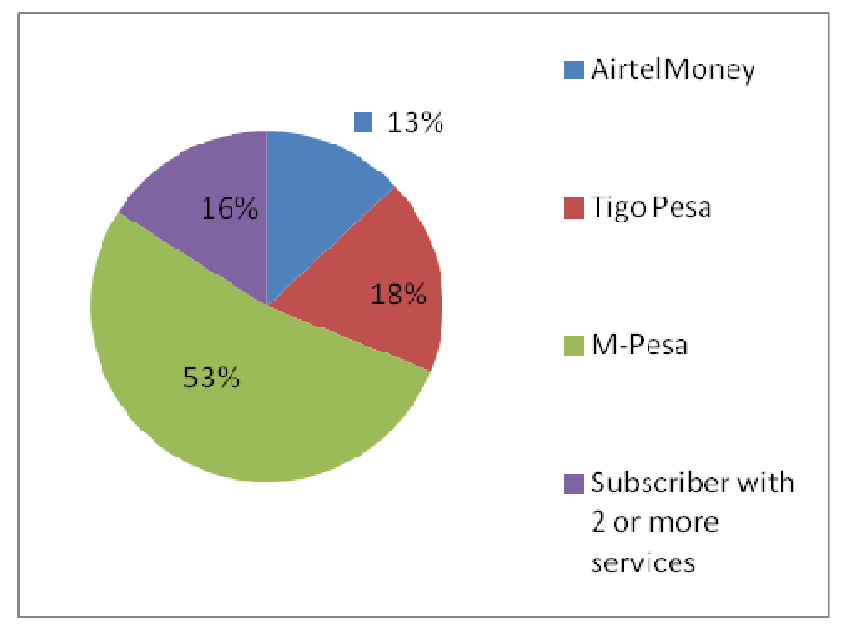

Figure 3: Mobile banking market share in Tanzania [6]

Furthermore, mobile banking agents are earning more profit compared to their regional peers. This is according to the report titled "Agent Network Accelerator Survey" that was conducted by Helix Institute of Digital Finance last year and published in April/2014 [13]. It also pointed out that rapid growth and non-exclusivity of agents is putting pressure on agents' liquidity. Almost two thirds of agents in rural Tanzania (see Figure 4) are still exclusive - M-Pesa agents. But this will change as more providers are expanding to accommodate rural areas and the introduction of interoperability will reduce the percentage of exclusivity.

\section{Exclusivity in Tanzania}

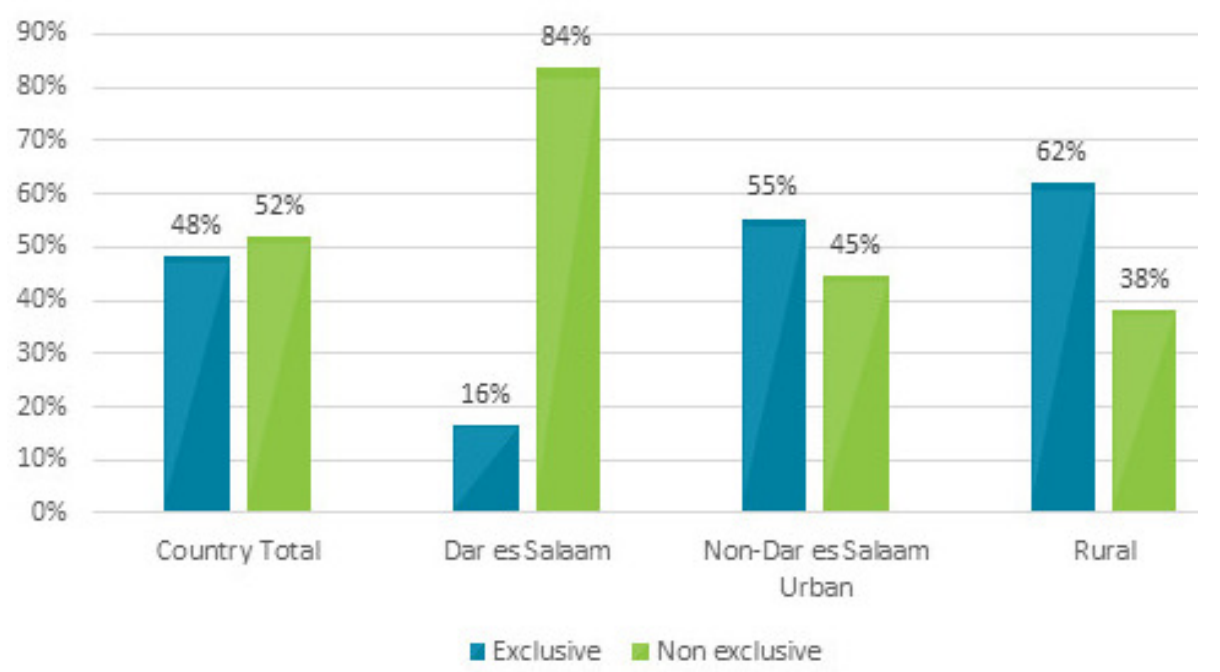

Figure 4: Mobile Banking Agent exclusivity in Tanzania [13] 
International Journal of Network Security \& Its Applications (IJNSA), Vol.6, No.4, July 2014

\section{MOBILE BANKING ECOSYSTEM IN TANZANIA}

According to [14], mobile banking platform involves several players and stakeholders who are involved with different roles and with diverse benefits from the whole mobile banking value chain. Mobile banking can open the door to increased revenues, cost savings, and improved customer experience to all participants of mobile banking ecosystem: Mobile network operators (MNO), payment networks, merchants and retailers, Agents, Users, Banks, Businesses, device manufacturers.

- In Mobile banking ecosystem, MNO provides the mobile infrastructure and customer base that is already using its communication services. In Tanzania, MNO ensures compliance with telecommunication regulations and policy as given by TCRA. Mobile banking offer a manifold of benefits to MNOs such as increasing and maintaining the number of customers, reducing the cost of airtime distribution and by generating new revenue.

- A bank or other financial institution with banking license and infrastructure that enables the exchange of money between different parties. These also provide oversight and regulatory compliance with Bank of Tanzania (BoT) financial regulations and policy. Banks are leverage mobile banking platforms to reach more customer previously underserved in remote areas with reasonable costs. For example, banks such as CRDB, NMB and NBC and other financial institutions, in collaboration with mobile network operators, have embarked on the provision of SMS banking services.

- Regulatory institutions in Tanzania include Central bank, Bank of Tanzania (BoT) for the financial issues and Tanzania Telecommunications Regulatory Authority (TCRA) regulates issues pertaining to communications infrastructure. For example, BoT signed an MOU with TCRA with the intention of sharing regulatory and supervisory information. Also, Tanzania is the member of Alliance for Financial Inclusion (AFI), which recently issued a Guideline note "Mobile Financial Service: Supervision and Oversight of Mobile Financial Services" to its members[15].

- An agent network that facilitates cash-in (converting cash into mobile money) and cashout (issuing cash on demand) to afford convertibility between mobile money and cash. MNOs in Tanzania have developed extensive agent networks to sell airtime and other products while those of the banks tend to be limited to urban or highly populated areas. Agents earn commission on various transactions carried out by mobile money users.

- Merchants and retailers, who accept mobile banking payments in exchange for different products and services. They help increase demand for mobile banking by offering more avenues through which users can spend their mobile banking. In return, they can minimise the need to handle cash.

- Businesses that utilize mobile banking as a means to deliver their services, i.e. MFIs, insurance providers, as well as large-scale disburse and bill issuers.

- Equipment manufacturers and platform providers include a wide array of stakeholders like mobile phone makers, network equipment vendors as well as application providers. These benefit from the increased sale of end-user devices like mobile phones, equipment to handle increased network capacity and fees or subscriptions respectively. 
- Mobile banking users are normally subscribers to and MNOs other services. Users derive benefits by getting cheaper and more efficient means of transferring or paying money to other people or businesses within the network.

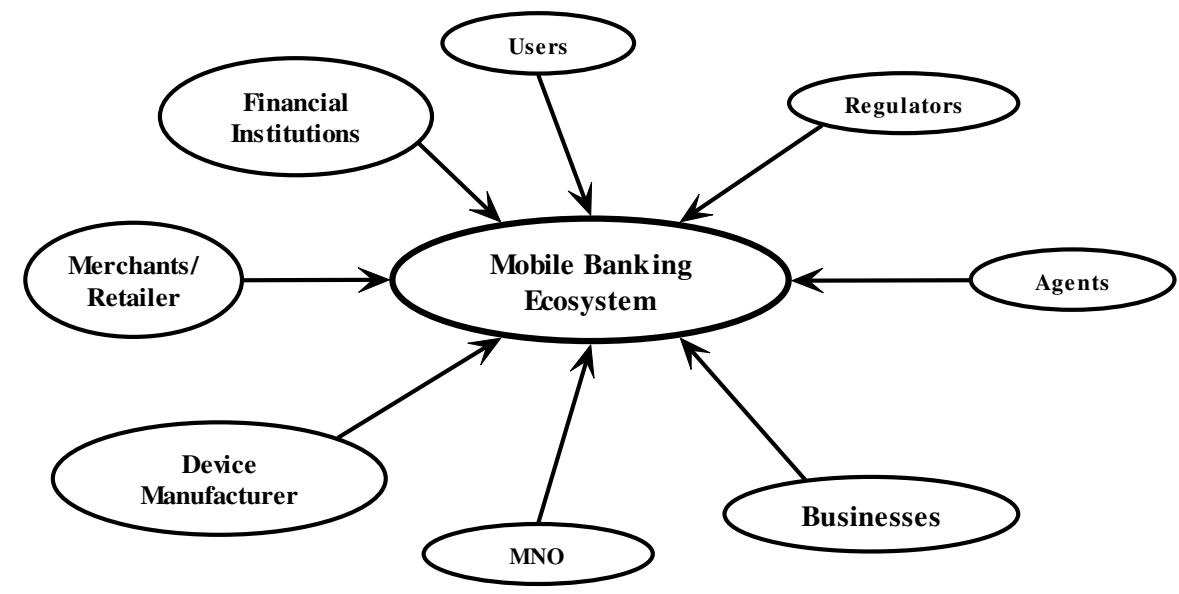

Figure 5: Mobile banking ecosystem in Tanzania

Within mobile banking ecosystem (as shown in Figure 4), collaboration is vital. Collaboration entails some challenges such as member ability to negotiate revenue-sharing and investment agreements, manage assets, integrate IT infrastructure, and make joint strategic decisions despite possibly differing priorities and goals. At times, some of the key players have encountered some difficulties in agreeing on a common approach because of the risks involved. On the contrary, the potential benefits of partnerships are likely greater than the incidental obstacles-effective cooperation (e.g. interoperability) could increase the total size of mobile banking market share, increasing the size of each players piece.

\section{SeCURity Challenges in Mobile banking}

Mobile devices have become both ubiquitous and indispensable for consumers and business people alike. Although these devices are relatively small and inexpensive, they are powerful with multiple functions [16]. The mobile devices have specialized built-in hardware, such as cameras, accelerometers, Global Positioning System (GPS) receivers, and removable media readers. Furthermore, they are integrated with multiple wireless communication technologies such as Wireless Fidelity (Wi-Fi), Bluetooth, Near Field Communications (NFC), and a cellular interfaces (that can be reconfigured to choose between CDMA or GSM) that provide network connectivity across the globe. These devices can be used for sending and receiving email, browsing the web, online banking and commerce, social networking, storing and modifying documents, remotely accessing data, recording audio and video, and as navigation aids.

According to [16] greater the number of functionality a mobile phone has, the more vulnerable mobile phones become to the same types of threats that plague our laptops and desktops computers. Current model of mobile devices are designed to make it easy to find, acquire, install, and use third-party applications. This poses obvious security risks, especially for mobile device platforms that do not place security restrictions or other limitations on third-party applications. These applications can be easily infected with mobile malware. Mobile malware, according to [17], are typically targeted more toward handheld devices for which an SDK is available than those without one, since code development is easier to perform. 
International Journal of Network Security \& Its Applications (IJNSA), Vol.6, No.4, July 2014

With multiple communication networks, mobile viruses and other form of malware can be delivered handheld devices from multiple channels. For instance, mobile malware may also be received during synchronization with desktop computers and via tainted storage media. Malware in mobile devices can be spread in a variety of ways, including the following common ones:

- Internet Downloads: A user with WAP or Wi-Fi enabled mobile phone may download an infected file via an Internet connection. The file could be disguised to trick the user. It appear as a game, security patch, utility, or it may be posted as a free or shareware download.

- Messaging Services: Malware attachments can be appended to electronic mail and MMS messages delivered to a device. Instant Messaging (IM) services supported on many phones are another means of malware delivery. In this attack, the user is forced to open the attachment, which subsequently the malware that will eventually infect the mobile phone.

- Bluetooth Communications: Bluetooth technology provides a means to link devices in close proximity for information exchange. Bluetooth device can be configured in discoverable or invisible mode. In discoverable mode, the device can be seen by other Bluetooth enabled devices from which communication can be established. Mobile phone malware can be delivered through this channel especially when the mobile phone is left in discoverable mode.

The consequences of mobile phone malware are wide. They can potentially eavesdrop on user activities, steal sensitive information, destroy stored information, deactivate or activate applications or disable a device. Mobile phone malware can initiate local or close proximity communications and propagate into other mobile devices or send via a mobile network (GSM/CDMA) premium rates text messages to services where the user is not subscribed or subscribed on other service rates.

Other security concerns worth discussing in mobile banking ecosystems are:

- Larger network that have emerged as the result of consolidation are prone to security implications. Applications for mobile payment solutions are complex in nature with mismatching set of possibilities that are caused by the involvement of multiple players. The lines differentiating these players have become blurred with the crossover of mobile phone. The benefit of consolidation and sharing infrastructure are apparent, but the costs of poor security are often distributed.

- Proliferation of mobile banking technologies has led to lack of cohesive technology standards that can provide a universal mode of mobile banking. This lack of common standard creates local and fragmented version of mobile banking offered by different stakeholders, which leads to lack of end-to-end security.

- In developing markets, mobile banking service providers depend on agents for customer acquisition and for managing liquidity. They access customer sensitive information such as the user name, mobile number and other credentials that are used for identification and authentication purpose. These agents are not well equipped to preserve customer sensitive information and can easily lead to information leakage.

Any loss of control over protected or sensitive information by service providers is a serious threat to business operations as well as, potentially, customer security. 
International Journal of Network Security \& Its Applications (IJNSA), Vol.6, No.4, July 2014

\section{CONSUMER DATA PRIVACY PROTECTION}

Privacy and data protection concerns are distinct issues that arise mobile banking transactions. They are linked to consumer protection policies within banking services and telecommunications, as well as certain practices in financial regulation. In mobile banking, which involves the transfer of electronic money between different parties, privacy is of great concern. For mobile banking scenario, data may include sender and receiver IDs, their geographic location, time of day, mobile numbers. If the transaction is for payment it may include: purchased items and their value and transaction value. These transactions create a data trail that could be used for various purposes good and bad.

Issues related to data protection are many as pointed out by [18]:

- Perpetrated on Consumers: In most of the developing market, mobile money users are less likely to be aware of the risks associate with warning signs thus making them more susceptible to fraud schemes. As the study conducted by [19] concludes, Vishing/Smishing scams that tricking customers into sharing personal information such as a PIN are common. As the study conducted by [20] in Tanzania shows, few users understands the concept of PIN and how to protect it. This is the concern to all stakeholders involved in mobile money as any fraud may lead to the loss of trust in mobile money services.

- Mobile Money Agent Misconduct: Agents are critical in most of mobile money business models. They are involved in customer registration and liquidity management, activities that expose them to customer's transaction details. Agents are not well equipped to preserve this sensitive information and any leakage may have negative consequence to customers. For example, female customers in some markets are reluctance to provide their phone numbers to agents for fear of harassment. Other issues such delayed and lost mobile money are common especially when sending mobile money to the customer from different service provider.

- Unclear or Inadequate Consumer Recourse: Some mobile money operators have set up exemplary call center operations with specialized staff who deal expeditiously with customer queries and complaints. This is not always the case, however, and we need to explore the extent to which consumers know where to turn, how accessible those recourse channels are, and whether their concerns are addressed in a timely and fair manner. A related area that needs attention is whether it is clear which financial service provider is ultimately responsible for resolving customer problems, when multiple businesses are involved in delivering the service as is increasingly common in the digital finance space.

\section{DISCUSSION AND CONCLUSION}

\subsection{DiSCUSSION}

Regulators for mobile banking in Tanzania like many others in developing countries are gradually changing as the mobile banking services evolve. According to[6], they are adapting "Test and Learn." They have to familiarise themselves with evolving issues such as technologies, business models, and commercial partnerships between banks and non-banking institutions. In other words, they are trying to understand a regulatory approach that will balance the interest of customers with those of market players. This approach require the regulators (i.e. TCRA and 
International Journal of Network Security \& Its Applications (IJNSA), Vol.6, No.4, July 2014

BOT) to develop the capacity to regulate and the authority to do so.

According to [11], financial legislation that influences the operations of Mobile Banking within The United Republic of Tanzania are:

- The Bank of Tanzania Act (BoT) (enacted 2006,165 repealing the act of 1995,166 which in turn repealed the act of 1965) - created the Bank of Tanzania and defines its principal functions.

- The Banking and Financial Institutions Act (enacted 2006)167-provides the legal framework for undertaking licensed banking operations within the United Republic of Tanzania.

- The Finance Act (enacted 2006)168 - through this legislation the Government regularly makes changes to the tax regime and amends different financial or tax laws.

- The Anti-Money Laundering Act, CAP 423 (2006)169 -helps address AML/CFT issues and established the Financial Intelligence Unit (FIU)170 in the Ministry of Finance and Economic Affairs as a unit mandated with enforcement.

- There are a number of guidelines from BoT that are relevant to mobile money including the National Payment Systems Guidelines for retail payments, Rules and Regulations for Retail payments and the Guidelines for introducing electronic payments.

Equally, telecommunication regulations that influence the conduct of mobile banking operations within The United Republic of Tanzania are:

- The United Republic of Tanzania Communications Regulatory Authority (TCRA) Act no. 12 (2003) that established and provides the mandate of the communications regulator. 172

- The Fair Competition Act (2003) is meant to foster competition in different sectors, while at the same time protecting consumers. As part of the Act, the Tanzanian Government has set up the Fair Competition Commission (FCC)-to administer the law and the Fair Competition Tribunal (FCT)-to provide a judicial forum where appeals of various commission decisions can be made.

- The United Republic of Tanzania Evidence Act, CAP 6 (2002) influences the treatment of electronic documents as evidence in Tanzanian courts.

- The Electronic and Postal Communications Act, 2010 (Act No. 3/10)

Other issues that rises concerns in mobile banking industry is regulatory infrastructure that regulates mobile money issuers with a wide range of payment services such as covering domestic and international remittances, utilities payments, interest and amortisation on loans, insurance premiums, school tuition, micro tax payments and business registration, airtime top-up. Also interoperability is another issue of concern. As mobile banking services continue to expand, interoperability will be key feature in mobile banking transactions. This feature (ability) will likely increase the use of mobile banking services. With the current system setup, a customer who wants to transfer money between mobile banking accounts (i.e. with different providers) must visiting an agent to cash out the desired amount of money from one provider and then carrying cash to an agent of another provider to cash in (i.e. to deposit) and paying any applicable commissions or agent fees. This consumes not only money for commission, but also time. 
International Journal of Network Security \& Its Applications (IJNSA), Vol.6, No.4, July 2014

In their publication [21] CGAP has defined three levels of interoperability that need to be addressed developing market such as Tanzania as:

- Platform-level interconnection: If mobile money platforms are interconnected, a customer with an account with one service provider can send or receive money to or from the account of a customer with a different service provider. To date platform-level interconnection has not been implemented widely.

- 2. Agent-level exclusivity: Agent exclusivity revolves around the ability of a customer of one provider to use the agent of another provider for cash-in/cash-out services related to that customer's account. Agent interoperability is possible even when there is agent exclusivity, as long as platforms are interconnected (such as with interoperable ATM networks).

- 3. Customer-level interoperability: This term is used to describe two interoperability scenarios related to the mobile handset:

1. a customer's ability to access his/her account using any phone with a SIM card on the same network

2. a customer's ability to access multiple accounts on one SIM

Figure 5 illustrates these interoperability levels in more detail.
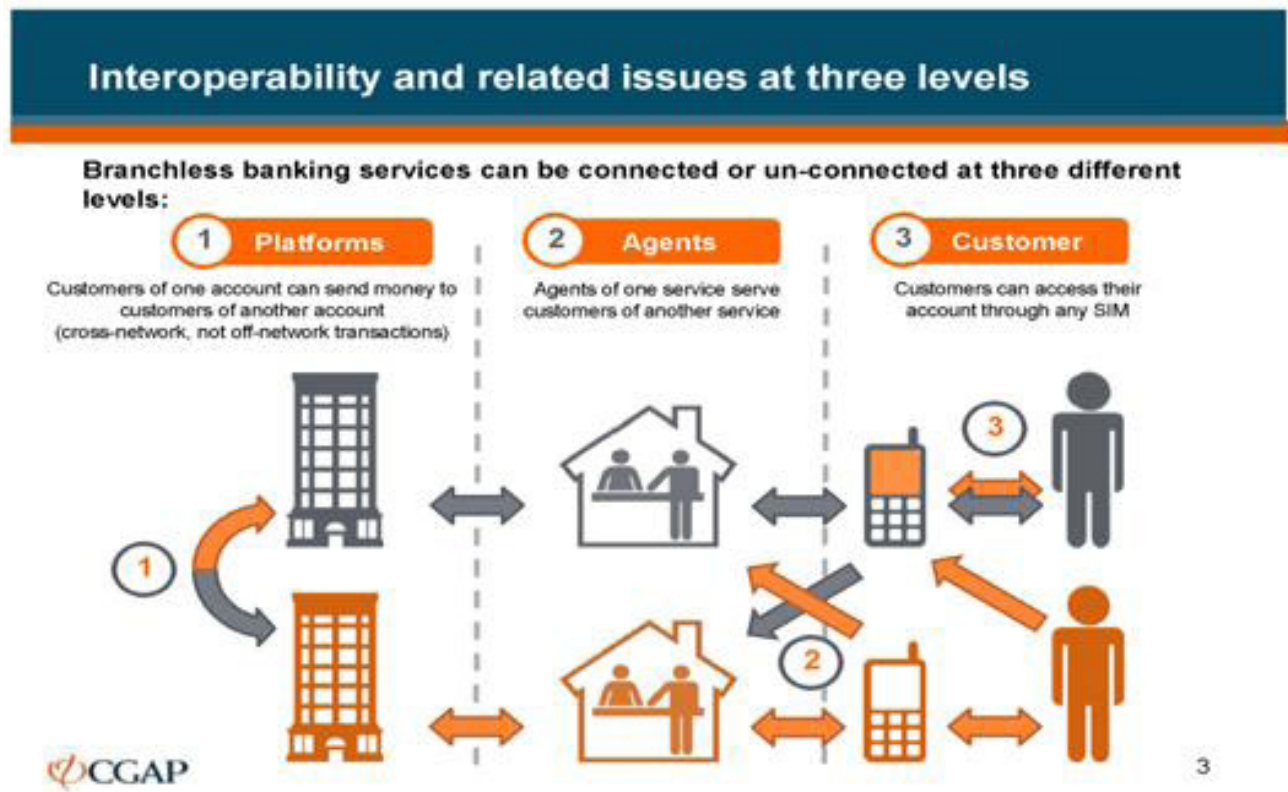

Figure 6: Interoperability issues [21]

Though three operators (Tigo, Airtel and Zantel) have agreed on interoperability, key issues must be addressed. For mobile banking to proliferate and scale, interoperability must be addressed to all participants in mobile banking ecosystem in order to accelerate the level of participation.

\section{CONCLUSION}

The growing increase in the use of the mobile phone and Internet broadband services and the recent introduction fiber optic network that is interconnect with sea cable are vital factors that push toward building a unified and integrated e-payment system that will contribute to reducing 
International Journal of Network Security \& Its Applications (IJNSA), Vol.6, No.4, July 2014

the time and effort needed to perform financial transactions, pay for products and services, settle civil liabilities owed to the government, or pay water, electricity, communications and other bills.

Electronic payments systems have proved to promote economic growth and contribute to a stable trade system, helping to stimulate growth and generate jobs, besides allowing for a better financial control for consumers, business and governments. In Tanzania market, participants of mobile banking ecosystem are becoming increasingly aware of the efficiency, reliability and practicality of mobile banking transactions when compared with other means of payment. Mobile banking will help Tanzania with her underdeveloped payment systems leapfrog traditional paperbased ways of making payments. There are multiple players in mobile banking systems that are competing in the market. In order to increase the penetration and adoption of mobile baking systems, alliance with other industries such as telecommunications, utility, retail, entertainment and financial institutions is a synergistic. Each of these industries collects bills from consumers, a process that is deemed to evolve into digital format more easily and lead to a powerful mobile banking ecosystem.

The expansion and countrywide use of mobile banking will depend on the coverage of communication networks. In addition, interoperable mobile banking systems will accelerate financial inclusion by allowing customers to use the infrastructure of multiple service providers to access their account. The introduction of sea cable for global high speed Internet connectivity and the expansion of mobile communication networks enhanced with $4 \mathrm{G}$ technologies will open new windows of business transactions. With well know payment networks such as MasterCard, consumers will make purchases from merchants of different countries. This will require all emerging electronic payment systems to provide international currency exchange for customers to trade globally. For example, Tigo Pesa has introduced cross-border service for their customers in both Tanzania and Rwanda. Furthermore due to the growing pervasiveness of mobile money platforms globally, standardization is vital. Recently, Airtel, Tigo and Zantel announced an agreement that will allow customers to send mobile money freely across their networks. It is the first true "interoperability" mobile money service. It allows their customers to send and receive money across networks and the mobile money goes directly to the respective customer's mobile money account[22].

Recently, the government launched the National Financial Inclusion Framework (NFIF) that reflects on AFIGI (Alliance for Financial Inclusion Global Initiative), known as "The Maya Declaration". With NFIF aiming to enable 50\% adult to have financial access by 2016, the future of mobile banking is bright.

\section{REFERENCES}

[1] Michaels, Loretta, "It's Better Than Cash: Kenya Mobile Money Market Assessment," Accenture Development Partnershipsm, Accenture.

[2] Claire, Penicaud and Katakam, Arunjay, "State of the Industry 2013: Mobile Financial Services for Unbanked," GSMA: Mobile Money for the Unbanked.

[3] Bot, "National Financial Inclusion Framework: A Public-Private Stakeholder Initiatives (20142016)," Bank of Tanzania.

[4] Tcra, "QUARTERLY TELECOM STATISTICS," http://www.tcra.go.tz/images/documents/telecommunication/telecomStatsJune13.pdf.

[5] Gsma, "Mobile for Development Intelligence: Products and Serviices," https://mobiledevelopmentintelligence.com/products.

[6] Di Castri, Simone, "Mobile Money: Enabling Regulatory Solutions," GSMA, London, United Kingdom. Available at http://www. gsma. com/mobilefordevelopment/wpcontent/uploads/2013/02/MMU-Enabling-Regulatory-Solutions-di-Castri-2013. pdf. 
[7] Mas, Ignacio and John, Agathamarie, "Where's the Cash? The Geography of Cash Points in Tanzania," The Geography of Cash Points in Tanzania (February 20, 2013). FSDT Focus Note.

[8] Vodacom, "Send Money by Phone with Vodacom M-Pesa," \{http://www.vodacom.co.tz/docs/\}, 2008.

[9] Davidson, Neil and Paul, Leishman, "Building a Network of Mobile Money Agent," \{http://www.mmublog.org/agent-networks \}.

[10] Cgap, "Vodacom Tanzania and CBA Launched M-Pawa, a Mobile Money Banking Product," http://www.microfinancegateway.org/p/site/m/template.rc/1.1.21703/, 2014.

[11] Unctad, "Mobile Money for Business Development in the East African Community," United Nations Conference on Trade and Development - UNCTAD.

[12] Ivatury, G., "Using technology to build inclusive financial systems," New Partnerships for Innovation in Microfinance, pp. 140-164, 2009.

[13] Mike Mccaffrey, Leena Anthony, Annabel Lee, Kimathi Githachuri, Graham A. N. Wright, "Agent Network Accelerator Survey: Tanzania Country Report 2013," Microsave, 2014.

[14] Jenkins, B., "Developing mobile money ecosystems," Washington, DC: International Finance Corporation and Harvard Kennedy School, 2008.

[15] Afi, "Mobile Financial Services: Supervision and Oversight of Mobile Financial Services," Alliance for Financial Inclusion, Bangkok, Technical February 20142014.

[16] Cheng, Zhu, "Mobile malware: Threats and prevention," McAfee Avert, 2007.

[17] Jansen, W. and Scarfone, K., "Guidelines on Cell Phone and PDA Security (Draft)," NIST Special Publication, vol. 800, pp. 124, 2008.

[18] Mckee, Kate and Zimmerman, Jamie, "Do Mobile Money Clients Need More Protection?" http://www.cgap.org/blog/do-mobile-money-clients-need-more-protection.

[19] Gilman, Lara and Joyce, Michael, "Managing the Risk of Fraud in Mobile Money," GSMA: Mobile Money for Unbanked (MMU).

[20] Intermedia, "Tanzania Mobile Money Tracker Study," InterMedia-www.intermedia.org.

[21] Tarazi, Kabir Kumar and Michael, "Interoperability and related issues in mobile money," CGAP, 2012.

[22] Mark, Okuttah, "Tanzania telcos in Africa's first 'interoperable' mobile money pact," 2014. 